\title{
Efficacy of Postoperative Adjuvant Chemotherapy According to Prognostic Factor in Patients with Stage III Colon Cancer
}

\author{
Kiichi Sugimoto, Kazuhiro Sakamoto, Yuichi Tomiki, Michitoshi Goto, Yutaka Kojima, \\ Hiromitsu Komiyama, Makoto Takahashi, Shun Ishiyama, Koichiro Niwa, Haruna Okubo \\ Department of Coloproctological Surgery, Juntendo University Faculty of Medicine, Tokyo, Japan \\ Email: ksugimo@juntendo.ac.jp
}

Received 25 April 2014; revised 23 May 2014; accepted 19 June 2014

Copyright (C) 2014 by authors and Scientific Research Publishing Inc.

This work is licensed under the Creative Commons Attribution International License (CC BY).

http://creativecommons.org/licenses/by/4.0/

(c) (i) Open Access

\begin{abstract}
Background: We retrospectively identified prognostic factors in patients with Stage III colon cancer and considered the effectiveness of postoperative adjuvant chemotherapy based on these prognostic factors. Methods: Two hundred and thirty four patients with lymph node metastases who underwent curative surgery for colon cancer between 1999 and 2005 were enrolled in the present study. Firstly, clinicopathological factors and survival data, were analyzed to determine prognostic factors related to cancer-specific survival. Secondly, we examined the effectiveness of postoperative adjuvant chemotherapy based upon these prognostic factors. Results: The multivariate analysis revealed that differentiation $(P=0.03$, Hazard ratio $=2.50)$, lymphatic invasion $(P=$ 0.02 , Hazard ratio $=3.23)$ and the TNM classification, $7^{\text {th }}$ edition $(P=0.04$, Hazard ratio $=1.94)$ were found to be significant independent prognostic factors. Among the patients classified as TNM IIIA, the recurrence-free survival rates were extremely good. Among the patients classified as IIIB and IIIC, there was no significant difference between the patients with and without postoperative adjuvant chemotherapy. Conclusion: The present study suggests that the patients with Stage IIIA colon cancer may not require postoperative adjuvant chemotherapy. The addition of oxaliplatin to 5-FU should be considered for the patients with Stage IIIB and IIIC colon cancer, for whom the prognoses are far from satisfactory.
\end{abstract}

\section{Keywords}

Colorectal Cancer, Postoperative Adjuvant Chemotherapy, Prognostic Factor, Stage III Colon Cancer, TNM Classification, $7^{\text {th }}$ Edition 


\section{Introduction}

Colorectal cancer is the second most common cause of cancer death in the United States and Japan, and its incidence is rapidly increasing in Japan [1] [2]. Stage III colon cancer is suitable for postoperative adjuvant chemotherapy, and intravenous Fluorouracil and Leucovorin therapy has been the therapeutic standard in the surgical adjuvant setting. Recently, the non-inferiority of UFT/LV [3] and Capecitabine [4] was demonstrated, and the efficacy of oral anti-cancer drugs, which are a convenient treatment method, has been recognized widely. Moreover, the efficacy of the addition of oxaliplatin to 5FU/LV in patients with Stage II or III colon cancer was proven in the NSABP C-07 trial [5] and in patients with Stage III colon cancer in the MOSAIC trial [6]. Many guidelines in the West recommend postoperative adjuvant chemotherapy with oxaliplatin for patients with Stage III colon cancer [7]-[9]. However, it has been pointed out that the addition of oxaliplatin can lead to peripheral sensory neuropathy [10] and increases medical expenses [11]. Therefore, it is extremely important to distinguish those Stage III patients for whom postoperative adjuvant chemotherapy with oxaliplatin may be unnecessary. We retrospectively identified prognostic factors in patients with Stage III colon cancer and considered the effectiveness of postoperative adjuvant chemotherapy based on these prognostic factors.

\section{Methods}

\subsection{Patient Selection}

Two hundred and thirty four patients with lymph node metastases who underwent curative surgery for colon cancer at our department between 1999 and 2005 were enrolled in the present study. We retrospectively reviewed the database and medical records. Cases with multiple primary cancer, preoperative adjuvant chemotherapy and radiotherapy and cases that died of non cancer-related causes were excluded from the present study. The median observation period was 63.9 months (range: 2.9 - 129.2 months).

\subsection{Postoperative Adjuvant Chemotherapy}

We recommended all eligible patients to receive postoperative adjuvant chemotherapy. Patients were considered ineligible if they had synchronous or metachronous multiple cancers, severe complications or were advanced in age. All of the eligible patients had an Eastern Cooperative Oncology Group performance status of 0, 1, or 2. All patients were required to provide informed consent. During the present study period, patients received 5-FU drugs orally for more than six months, starting 4 - 8 weeks after surgery. We did not perform preoperative adjuvant chemotherapy at our department because preoperative adjuvant chemotherapy was not popular in Japan during the present study period.

\subsection{Clinicopathological Analysis}

Firstly, clinicopathological factors, i.e., age ( $<75 / \geq 75$ years), gender (male/female), location (proximal/distal), preoperative serum CEA (normal/elevated), differentiation (well- or moderately-differentiated adenocarcinoma/ others), invasion depth (the TNM classification, $7^{\text {th }}$ edition: (T1 - T3)/T4), lymphatic invasion (none-mild/moderate-severe), venous invasion (none-mild/moderate-severe), the number of dissected lymph nodes $(\leq 11 / \geq 12)$, the TNM classification, $7^{\text {th }}$ edition (IIIA, IIIB/IIIC) and survival data, were analyzed to determine prognostic factors related to cancer-specific survival. Secondly, we examined the effectiveness of postoperative adjuvant chemotherapy based upon these prognostic factors.

\subsection{Pathological Examination}

All specimens were examined in the following manner [12]: After resection of the primary tumor, the excised specimen was opened on the antimesenteric side by the surgeon. The surgeon identified the lymph nodes, isolated them, and recorded both their number and distribution. After formalin fixation, the specimens and lymph nodes were examined by the pathologist.

\subsection{Follow-Up Program}

During the first 3 years, patients were followed every 3 months with clinical assessment and measurement of se- 
rum carcinoembryonic antigen, and every 3 - 6 months with chest X-ray and abdominal ultrasonography or computed tomography. For the remaining 2 years, all tests were performed every 6 months. Colonoscopy was performed 1 year after the operation and every 2 years for the next 4 years.

\subsection{Statistical Analysis}

The recurrence-free survival rate and the cancer-specific survival rate were calculated using the Kaplan-Meier method and univariate analyses were performed using the log-rank test. Clinicopathological factors, for which there were significant differences in the univariate analysis, were used as co-variables for the multivariate analysis. For the multivariate analysis, the Cox proportional-hazard model was used with the Hazard ratio as a measure of association, by applying a stepwise procedure. Data were analyzed statistically using JMP 9.0.2 software (SAS Institute Inc., Cary, NC, USA). Differences were considered statistically significant at $\mathrm{P}<0.05$. Values are expressed as the median (min.-max.).

\section{Results}

\subsection{Patient Characteristics}

The patient characteristics are shown in Table 1. One hundred and sixty two patients (69.2\%) underwent postoperative adjuvant chemotherapy. Details of the regimens and doses of postoperative adjuvant chemotherapy are shown in Table 2. The durations of postoperative adjuvant chemotherapy were from six months to one year in 67 patients (41.4\%), from one to two years in 29 patients (17.9\%) and more than two years in 56 patients (34.6\%). Ten patients (6.2\%) discontinued postoperative adjuvant chemotherapy within less than six months because of recurrence.

\subsection{Comparisons of the Clinicopathological Factors between the Patients with and without Postoperative Adjuvant Chemotherapy}

In univariate analysis, there were significant differences in the age, invasion depth, lymphatic invasion and venous invasion between the patients with and without postoperative adjuvant chemotherapy; in the postoperative adjuvant chemotherapy $(+)$ group, there were significantly more patients aged 74 years old or less $(\mathrm{P}<0.001)$, with an invasion depth of T4 $(\mathrm{P}=0.008)$, moderate-severe lymphatic invasion $(\mathrm{P}=0.02)$ and moderate-severe venous invasion $(\mathrm{P}=0.001)$ (Table 3$)$. There were no significant differences between the two groups with

\begin{tabular}{|c|c|c|}
\hline & \multicolumn{2}{|c|}{ No. of patients (\%) } \\
\hline Total & \multicolumn{2}{|c|}{234} \\
\hline Age & \multicolumn{2}{|c|}{66 years $(30-90)$} \\
\hline \multicolumn{3}{|l|}{ Location } \\
\hline Proximal & 70 & $(29.9 \%)$ \\
\hline Distal & 164 & $(70.1 \%)$ \\
\hline \multicolumn{3}{|c|}{ TNM classification, $7^{\text {th }}$ edition } \\
\hline IIIA & 37 & $(15.8 \%)$ \\
\hline IIIB & 155 & $(66.2 \%)$ \\
\hline IIIC & 42 & $(18.0 \%)$ \\
\hline \multicolumn{3}{|c|}{ Postoperative adjuvant chemotherapy ${ }^{a}$} \\
\hline$(+)$ & 162 & $(69.2 \%)$ \\
\hline$(-)$ & 72 & $(30.8 \%)$ \\
\hline
\end{tabular}


Table 2. Details of the regimens and doses of postoperative adjuvant chemotherapy.

\begin{tabular}{|c|c|c|c|c|}
\hline Regimens & Doses (mg/day) ${ }^{\mathrm{a}}$ & & \multicolumn{2}{|c|}{ No. of patients (\%) } \\
\hline Fluorouracil & $\begin{array}{c}<200 \\
200 \leq \quad<300 \\
300 \leq\end{array}$ & Subtotal & $\begin{array}{c}45 \\
19 \\
2 \\
66\end{array}$ & $\begin{array}{c}(27.8 \%) \\
(11.7 \%) \\
(1.2 \%) \\
(40.7 \%)\end{array}$ \\
\hline $\begin{array}{l}\text { Tegafur-uracil } \\
\text { combination }\end{array}$ & $\begin{array}{c}<300 \\
300 \leq \quad<600 \\
600 \leq\end{array}$ & Subtotal & $\begin{array}{c}12 \\
51 \\
2 \\
65\end{array}$ & $\begin{array}{c}(7.4 \%) \\
(31.5 \%) \\
(1.2 \%) \\
(40.1 \%)\end{array}$ \\
\hline $\begin{array}{c}\text { Tegafur-gimeracil-oteracil } \\
\text { combination }\end{array}$ & $\begin{array}{c}<0 \leq \quad<0 \\
8120 \\
120 \leq\end{array}$ & Subtotal & $\begin{array}{c}1 \\
11 \\
2 \\
14\end{array}$ & $\begin{array}{l}(0.6 \%) \\
(6.8 \%) \\
(1.2 \%) \\
(8.6 \%)\end{array}$ \\
\hline Doxifluridine & $\begin{array}{c}<800 \\
800 \leq \quad<1200 \\
1200 \leq\end{array}$ & Subtotal & $\begin{array}{c}10 \\
3 \\
0 \\
13\end{array}$ & $\begin{array}{l}(6.2 \%) \\
(1.8 \%) \\
(0.0 \%) \\
(8.0 \%)\end{array}$ \\
\hline Carmofur & $\begin{array}{c}<300 \\
300 \leq \quad<600 \\
600 \leq\end{array}$ & & $\begin{array}{l}1 \\
3 \\
0\end{array}$ & $\begin{array}{l}(0.6 \%) \\
(1.8 \%) \\
(0.0 \%)\end{array}$ \\
\hline & & Subtotal & 4 & (2.4\%) \\
\hline & & Total & 162 & $(100 \%)$ \\
\hline
\end{tabular}

${ }^{\mathrm{a}}$ Upper section: less than the recommended dose; middle section: recommended dose; lower section: more than the recommended dose at every regimen.

Table 3. Comparisons of the clinicopathological factors between the patients with and without postoperative adjuvant chemotherapy.

\begin{tabular}{|c|c|c|c|c|}
\hline \multirow{2}{*}{$\begin{array}{l}\text { Clinicopathological } \\
\text { factors }\end{array}$} & \multirow{2}{*}{ Variables } & \multicolumn{2}{|c|}{ Postoperative adjuvant chemotherapy } & \multirow[t]{2}{*}{ P-value } \\
\hline & & Present $(n=162)$ & Absent $(\mathrm{n}=72)$ & \\
\hline \multirow{2}{*}{ Age } & $\geq 75$ & 15 & 27 & \multirow{2}{*}{$<0.001$} \\
\hline & $<75$ & 147 & 45 & \\
\hline \multirow{2}{*}{ Gender } & Male & 96 & 36 & \multirow{2}{*}{0.20} \\
\hline & Female & 66 & 36 & \\
\hline \multirow{2}{*}{ Location } & Proximal & 51 & 19 & \multirow{2}{*}{0.54} \\
\hline & Distal & 111 & 53 & \\
\hline \multirow{2}{*}{ Preoperative CEA } & Elevated & 71 & 30 & \multirow{2}{*}{0.78} \\
\hline & Normal & 91 & 42 & \\
\hline \multirow{2}{*}{ Differentiation } & Low grade ${ }^{\mathrm{a}}$ & 151 & 67 & \multirow{2}{*}{$>0.99$} \\
\hline & High grade $^{\mathrm{b}}$ & 11 & 5 & \\
\hline \multirow{2}{*}{ Invasion depth } & $\mathrm{T} 1$ - T3 & 94 & 55 & \multirow{2}{*}{0.008} \\
\hline & $\mathrm{T} 4$ & 68 & 17 & \\
\hline \multirow{2}{*}{ Lymphatic invasion } & None-mild & 46 & 32 & \multirow{2}{*}{0.02} \\
\hline & Moderate-severe & 116 & 40 & \\
\hline \multirow{2}{*}{ Venous invasion } & None-mild & 79 & 52 & \multirow{2}{*}{0.001} \\
\hline & Moderate-severe & 83 & 20 & \\
\hline \multirow{2}{*}{ No. of dissected lymph nodes } & $\geq 12$ & 129 & 53 & \multirow{2}{*}{0.31} \\
\hline & $<12$ & 33 & 19 & \\
\hline \multirow{2}{*}{ TNM classification, $7^{\text {th }}$ edition } & IIIA, IIIB & 129 & 63 & \multirow{2}{*}{0.20} \\
\hline & IIIC & 33 & 9 & \\
\hline
\end{tabular}

${ }^{\mathrm{a}}$ Well- and moderately-differentiated adenocarcinoma; ${ }^{\mathrm{b}}$ Poorly-differentiated or mucinous adenocarcinoma or signet ring cell carcinoma. 
respect to the other clinicopathological factors.

\subsection{Recurrence-Free Survival and Cancer-Specific Survival in All Patients}

Among all patients, the 5-year recurrence-free and cancer-specific survival rates were $64.3 \%$ and $78.3 \%$, respectively (Figure 1(a), Figure 1(b)).

\subsection{Prognostic Factors Related to the Cancer-Specific Survival in All Patients}

Comparisons of the cancer-specific survival rates according to clinicopathological factors are shown in Table 4. Significant differences in the cancer-specific survival rates were recognized for differentiation (other than wellor moderately-differentiated adenocarcinoma; $\mathrm{P}=0.01$ ), invasion depth (T4; $\mathrm{P}<0.001$ ), lymphatic invasion (moderate-severe; $\mathrm{P}<0.001$ ), venous invasion (moderate-severe; $\mathrm{P}<0.001$ ) and the TNM classification, $7^{\text {th }}$ edition (IIIC; $\mathrm{P}<0.001$ ). There were no significant differences with respect to the other clinicopathological factors. When these clinicopathological factors were used as co-variables for the multivariate analysis, differentiation (other than well- or moderately-differentiated adenocarcinoma; $\mathrm{P}=0.03$, Hazard ratio $=2.50$ ), lymphatic invasion (moderate-severe; $\mathrm{P}=0.02$, Hazard ratio $=3.23$ ) and the TNM classification, $7^{\text {th }}$ edition (IIIC; $\mathrm{P}=0.04$, Hazard ratio $=1.94$ ) were found to be significant independent prognostic factors (Table 5). With respect to the other clinicopathological factors, none were found to be independent factors. Comparisons of the cancer-specific survival rates according to the TNM classification, $7^{\text {th }}$ edition, are shown in Figure 2 . The cancer-specific survivals were well-stratified $(\mathrm{P}<0.001)$.

\subsection{The Effectiveness of Postoperative Adjuvant Chemotherapy According to the TNM Classification, $7^{\text {th }}$ Edition}

Among the patients classified as TNM IIIA, the 5-year recurrence-free survival rates in patients with and without postoperative adjuvant chemotherapy were $90.9 \%$ and $100 \%$, respectively. The recurrence-free survival rates in the two groups were extremely good and there was no significant difference between the two groups $(\mathrm{P}=0.25$; Figure 3(a)). The 5-year cancer-specific survival rates in patients with and without postoperative adjuvant che-

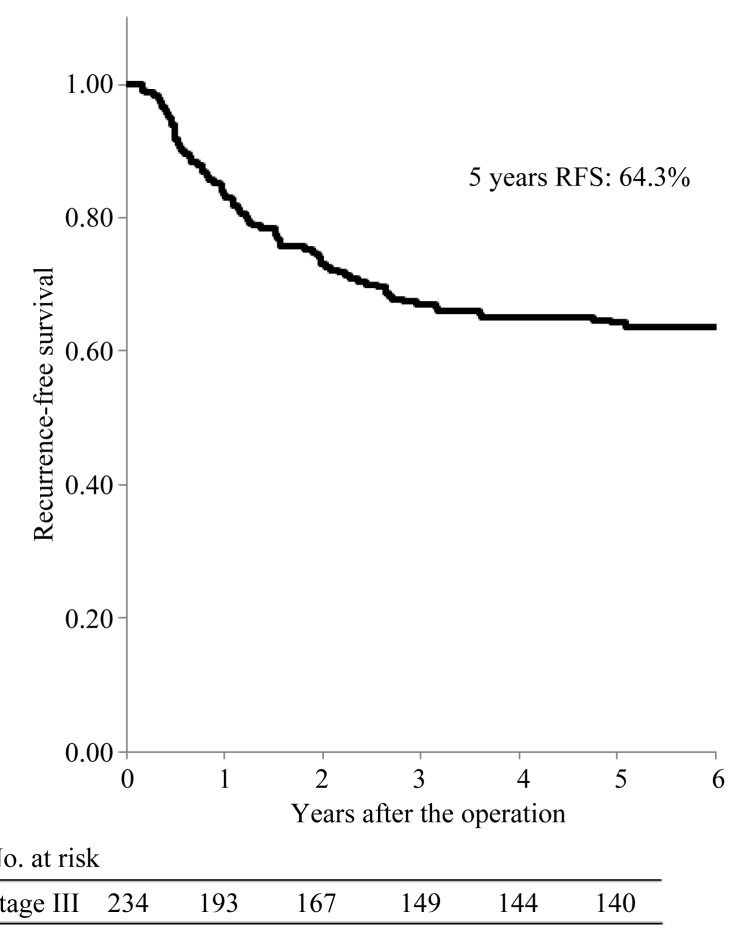

(a)

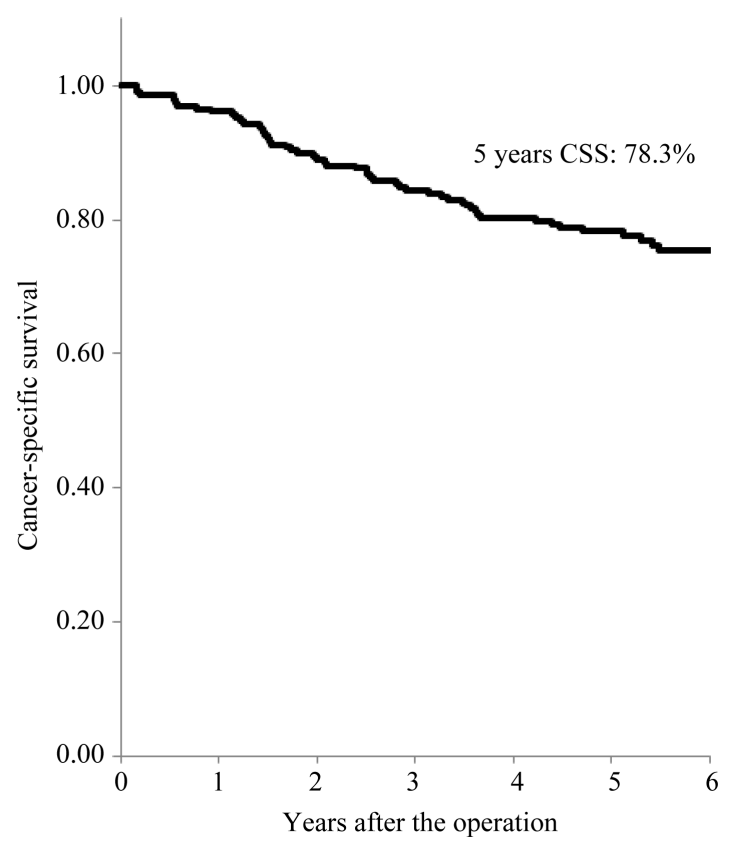

\begin{tabular}{lllllll} 
No. at risk \\
\hline Stage III & 234 & 220 & 198 & 181 & 167 & 158 \\
\hline
\end{tabular}

(b)

Figure 1. Recurrence-free and cancer-specific survival among all patients. 
Table 4. Comparisons of cancer-specific survival rates according to clinicopathological factors.

\begin{tabular}{|c|c|c|c|c|}
\hline Clinicopathological factors & Variables & No. of patients & $5 y$ CSS rates ${ }^{\mathrm{a}}(\%)$ & P-value \\
\hline \multirow[b]{2}{*}{ Age } & $75 \leq$ & 42 & 73.5 & \multirow[b]{2}{*}{0.50} \\
\hline & $<75$ & 192 & 79.1 & \\
\hline \multirow{3}{*}{ Gender } & Male & 132 & 78.6 & \multirow{3}{*}{0.79} \\
\hline & Female & & & \\
\hline & & & & \\
\hline \multirow{3}{*}{ Location } & Proximal & 70 & 78.6 & \multirow{3}{*}{0.86} \\
\hline & & & & \\
\hline & Distal & 164 & 78.2 & \\
\hline \multirow{3}{*}{ Preoperative CEA } & Elevated & 135 & 77.5 & \multirow{3}{*}{0.34} \\
\hline & & & & \\
\hline & Normal & 99 & 81.8 & \\
\hline \multirow[b]{2}{*}{ Differentiation } & Low grade ${ }^{\mathrm{b}}$ & 218 & 79.9 & \multirow[b]{2}{*}{0.01} \\
\hline & High grade $^{c}$ & 16 & 56.3 & \\
\hline \multirow{3}{*}{ Invasion depth } & $\mathrm{T} 1-\mathrm{T} 3$ & 149 & 86.8 & \multirow{3}{*}{$<0.001$} \\
\hline & & & & \\
\hline & $\mathrm{T} 4$ & 85 & 62.3 & \\
\hline \multirow{2}{*}{ Lymphatic invasion } & None-mild & 78 & 94.3 & \multirow[b]{2}{*}{$<0.001$} \\
\hline & Moderate-severe & 156 & 70.6 & \\
\hline \multirow{3}{*}{ Venous invasion } & None-mild & 131 & 88.1 & \multirow{3}{*}{$<0.001$} \\
\hline & & 103 & 65.4 & \\
\hline & Moderate-severe & 103 & 65.4 & \\
\hline \multirow{2}{*}{ No. of dissected lymph nodes } & $12 \leq$ & 182 & 78.6 & \multirow{2}{*}{0.93} \\
\hline & $<12$ & 52 & 77.4 & \\
\hline \multirow{2}{*}{ TNM classification, $7^{\text {th }}$ edition } & IIIA, IIIB & 192 & 83.4 & \multirow{2}{*}{$<0.001$} \\
\hline & IIIC & 42 & 54.9 & \\
\hline
\end{tabular}

${ }^{\mathrm{a}} 5$ years cancer-specific survival rates; ${ }^{\mathrm{b}}$ Well- and moderately-differentiated adenocarcinoma; ${ }^{\mathrm{C}}$ Poorly-differentiated or mucinous adenocarcinoma or signet ring cell carcinoma.

Table 5. Prognostic factors related to cancer-specific survival using Cox’s proportional hazards model.

\begin{tabular}{|c|c|c|c|}
\hline Prognostic factor & P-value & Hazard ratio & 95\% Confidence interval \\
\hline Differentiation (High grade ${ }^{a}$ ) & 0.03 & 2.50 & $1.11-5.63$ \\
\hline Invasion depth (T4) & 0.09 & 1.74 & $0.90-3.35$ \\
\hline Lymphatic invasion (Moderate-severe) & 0.02 & 3.23 & $1.23-8.50$ \\
\hline Venous invasion (Moderate-severe) & 0.15 & 1.61 & $0.85-3.04$ \\
\hline TNM classification, $7^{\text {th }}$ edition (IIIC) & 0.04 & 1.94 & $1.01-3.70$ \\
\hline
\end{tabular}

${ }^{\text {a }}$ Poorly-differentiated or mucinous adenocarcinoma or signet ring cell carcinoma.

motherapy were $95.5 \%$ and $100 \%$, respectively. There was no significant difference between the two groups (P $=0.44$; Figure 3(b)). Among the patients classified as IIIB, the 5-year recurrence-free survival rates in patients with and without postoperative adjuvant chemotherapy were $66.9 \%$ and $58.1 \%$, respectively. There was no significant difference between the two groups $(P=0.14$; Figure 4(a)). The 5-year cancer-specific survival rates in patients with and without postoperative adjuvant chemotherapy were $85.3 \%$ and $67.1 \%$, respectively. There was a significant difference between the two groups $(\mathrm{P}=0.008$; Figure 4(b)). Among the patients classified as IIIC, the 5-year recurrence-free survival rates in patients with and without postoperative adjuvant chemotherapy were 


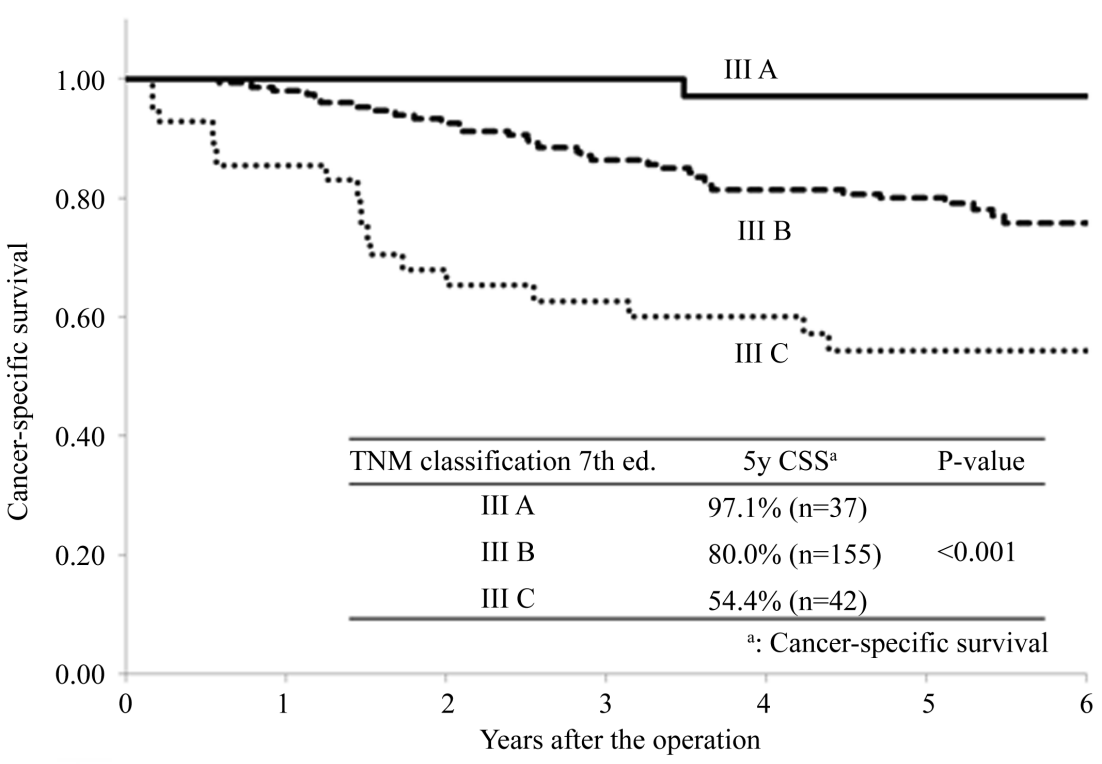

No. at risk

\begin{tabular}{lllllll}
\hline III A & 37 & 37 & 37 & 35 & 32 & 30 \\
III B & 155 & 148 & 135 & 122 & 113 & 110 \\
III C & 42 & 35 & 26 & 24 & 22 & 18 \\
\hline
\end{tabular}

Figure 2. Comparisons of the cancer-specific survival rates according to TNM classification $7^{\text {th }}$ ed.

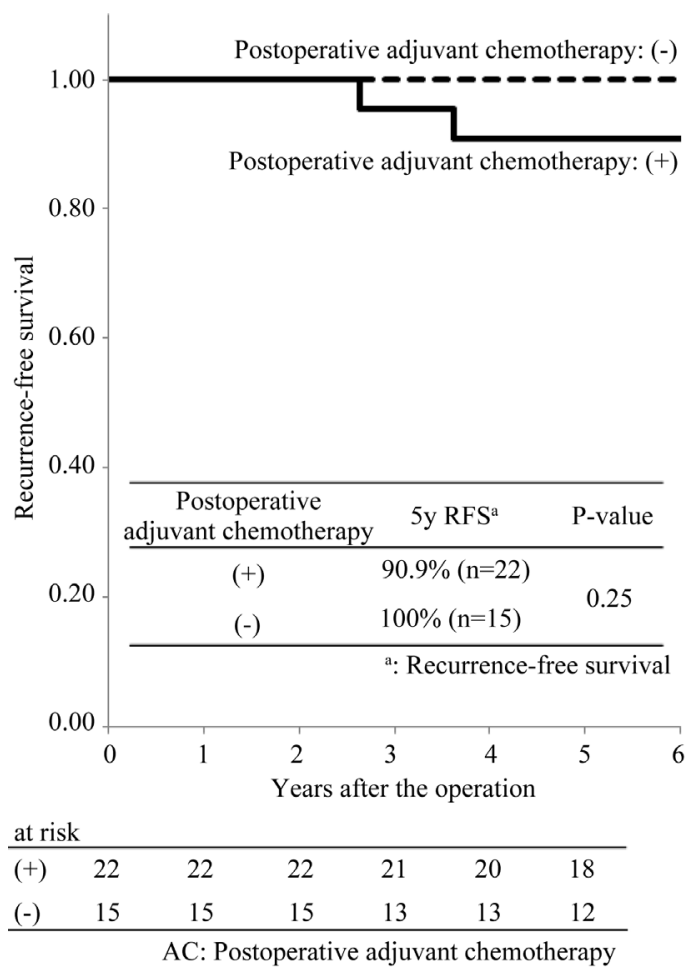

(a)

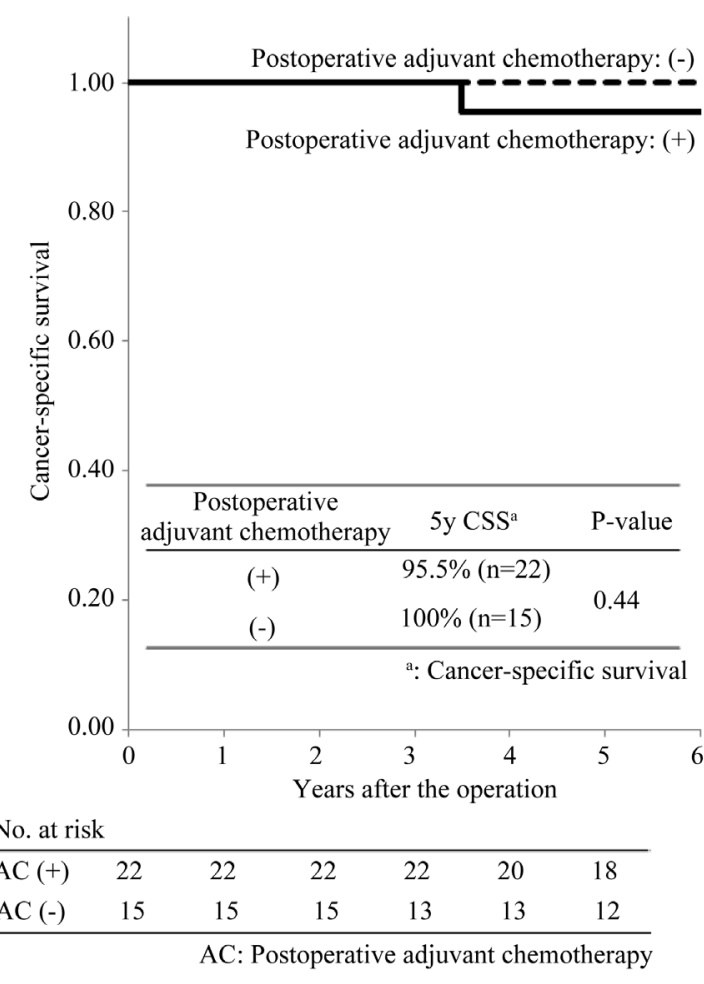

(b)

Figure 3. Recurrence-free and cancer-specific survival among the patients classified as TNM III A.

$42.4 \%$ and $22.2 \%$, respectively. The recurrence-free survival rates in the two groups were low and there was no significant difference between the two groups $(\mathrm{P}=0.20$; Figure 5(a)). The 5-year cancer-specific survival rates 

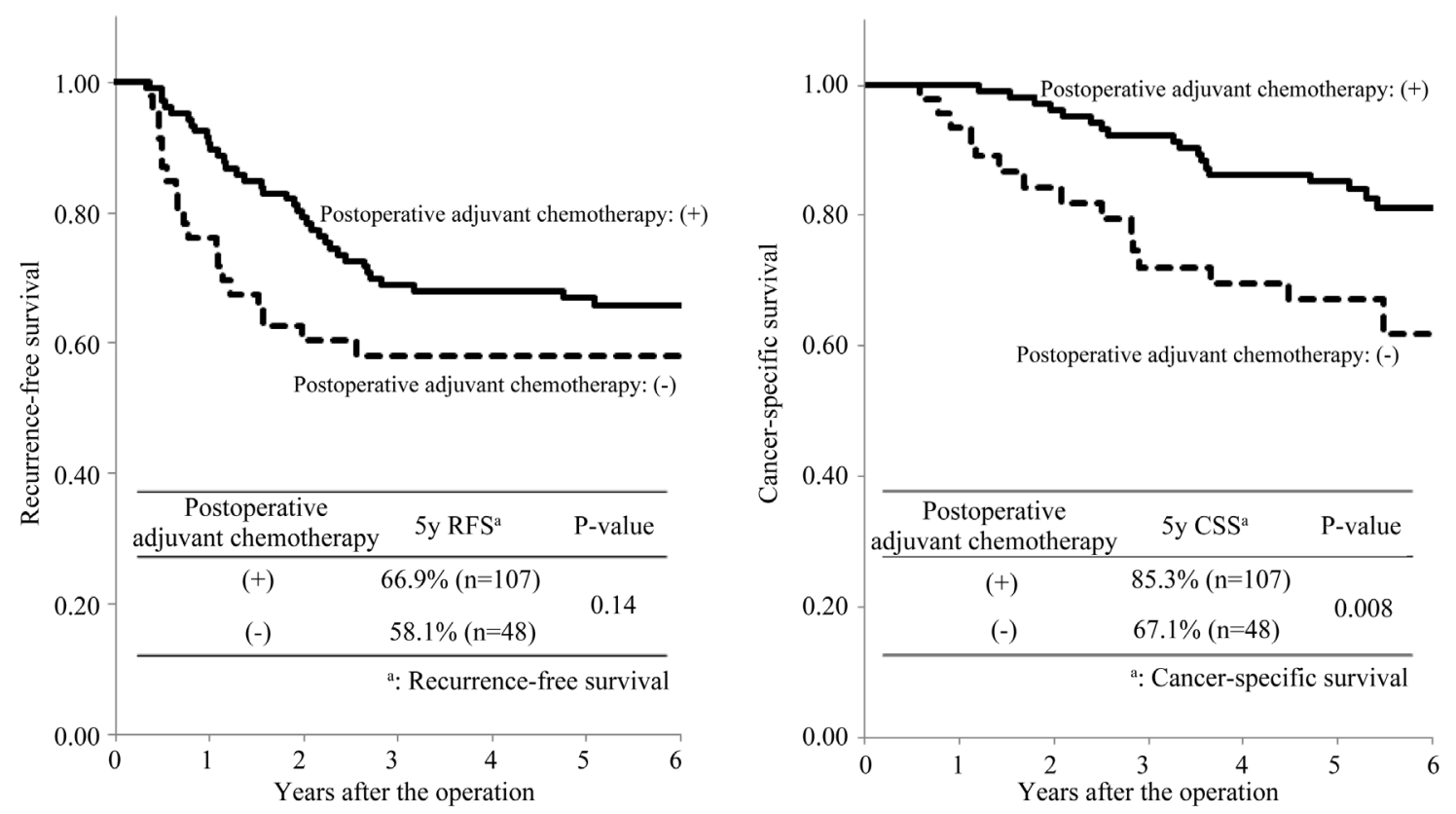

\begin{tabular}{|c|c|c|c|c|c|c|}
\hline No. at ri & & & & & & \\
\hline $\mathrm{AC}(+)$ & 107 & 96 & 84 & 72 & 71 & 70 \\
\hline $\mathrm{AC}(-)$ & 48 & 35 & 26 & 25 & 25 & 24 \\
\hline
\end{tabular}

(a)

\begin{tabular}{lcccccc} 
No. at risk \\
\hline AC (+) & 107 & 105 & 100 & 93 & 85 & 83 \\
AC (-) & 48 & 43 & 35 & 29 & 28 & 27 \\
\hline \multicolumn{7}{c}{ AC: Postoperative adjuvant chemotherapy }
\end{tabular}

(b)

Figure 4. Recurrence-free and cancer-specific survival among the patients classified as TNM III B.
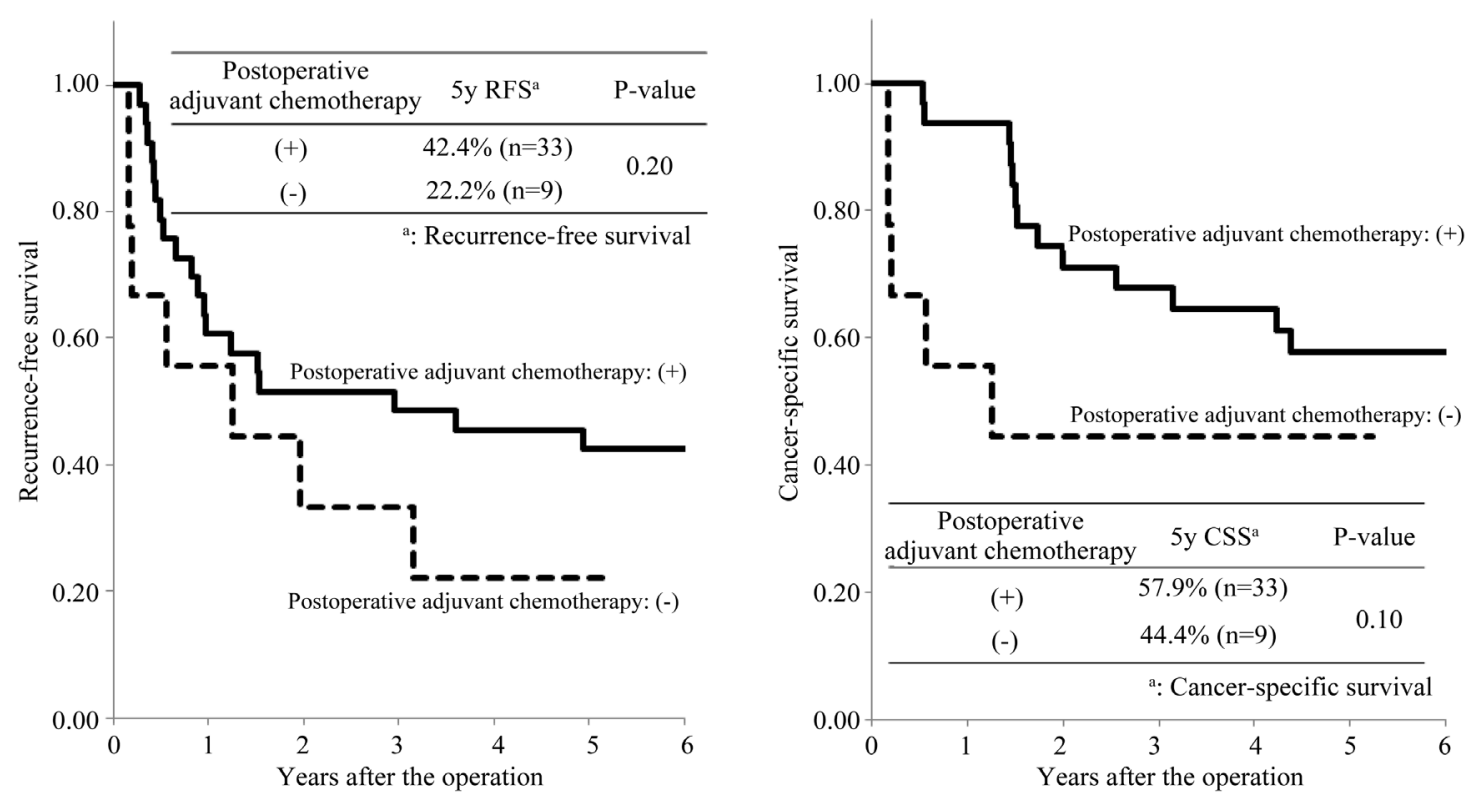

\begin{tabular}{lcccccc} 
No. at risk \\
\hline $\mathrm{AC}(+)$ & 33 & 20 & 17 & 16 & 15 & 14 \\
$\mathrm{AC}(-)$ & 9 & 5 & 3 & 3 & 2 & 2 \\
\hline
\end{tabular}

AC: Postoperative adjuvant chemotherapy

(a)

\begin{tabular}{lcccccc} 
No. at risk \\
\hline $\mathrm{AC}(+)$ & 33 & 30 & 23 & 21 & 20 & 16 \\
$\mathrm{AC}(-)$ & 9 & 5 & 3 & 3 & 2 & 2 \\
\hline \multicolumn{7}{c}{ AC: Postoperative adjuvant chemotherapy }
\end{tabular}

(b)

Figure 5. Recurrence-free and cancer-specific survival among the patients classified as TNM III C. 
in patients with and without postoperative adjuvant chemotherapy were $57.9 \%$ and $44.4 \%$, respectively. There was no significant difference between the two groups $(\mathrm{P}=0.10$; Figure $5(\mathrm{~b})$ ).

\section{Discussion}

In the postoperative adjuvant setting for colon cancer, even patients who can possibly be completely cured by surgery alone may receive adjuvant chemotherapy. Due to the context of "adjuvant therapy", severe adverse events, remarkable deterioration of quality of life and excessive burden of medical expenses cannot be permitted. It is necessary that the patients receive a proper protocol of chemotherapy that is a well-balanced between the expected efficacy and adverse events, quality of life and cost. Therefore, it is necessary to select the appropriate protocol according to the prognostic factors. We retrospectively identified prognostic factors in patients with Stage III colon cancer. We then considered the effectiveness of postoperative adjuvant chemotherapy based on these prognostic factors. The reasons why we adopted the TNM classification, $7^{\text {th }}$ edition, as a prognostic factor were as follows: in univariate analysis, there was a significant difference in lymphatic invasion between the patients with and without postoperative adjuvant chemotherapy. It must be considered there was a bias that the patients with moderate-severe lymphatic invasion tended to receive postoperative adjuvant chemotherapy more than those with none-mild lymphatic invasion. In addition, there were only sixteen patients with poorly-differentiated or mucinous adenocarcinoma or signet ring cell carcinoma. Therefore, although the Hazard ratio was higher in lymphatic invasion or in differentiation than in the TNM classification, $7^{\text {th }}$ edition, we adopted the TNM classification, $7^{\text {th }}$ edition, as a prognostic factor.

The TNM classification, $7^{\text {th }}$ edition, is based upon the invasion depth and the number of metastatic lymph nodes [13]. The validity of the stage classification has been confirmed by inspection of a database of more than 100,000 colorectal cancer patients [14] [15]. In particular, the patients in T1-T2N1 and T1N2a are classified as Stage IIIA in the TNM classification, $7^{\text {th }}$ edition, and these Stage IIIA patients have a good prognosis [14] [15]. In other words, these patients with a good prognosis can be distinguished from those Stage III patients who have a poor prognosis by using the TNM classification, $7^{\text {th }}$ edition. When considering the indications and protocol for postoperative adjuvant chemotherapy, it is essential to distinguish Stage IIIA patients from the remaining Stage III patients. In the present study, the 5-year cancer-specific survival in the patients with Stage IIIA colon cancer was $97.1 \%$ and was extremely good. On the other hand, the 5-year cancer-specific survival in the patients with Stage IIIC was $54.4 \%$ and was extremely poor. Consequently, Stage III was classified well. Gao et al. [16] reported that the TNM classification, $7^{\text {th }}$ edition, was sufficiently capable of predicting prognosis in the patients with Stage III colon cancer.

With respect to postoperative adjuvant chemotherapy, meta-analysis has revealed that oral adjuvant therapy after resection of colorectal cancer improved disease-free survival and overall survival in the Stage III patients [17]. Recently, some representative RCTs [5] [6] have proven the efficacy of the addition of oxaliplatin to 5FU/LV in the Stage III patients. Consequently, adjuvant chemotherapy with oxaliplatin for the patients with Stage III colon cancer is recommended in European and American guidelines [7]-[9]. These guidelines recommend the addition of oxaliplatin for the patients with Stage IIIA who have a good prognosis. However, because in the present study the prognosis in the patients with Stage IIIA was extremely good, patients with Stage IIIA may not require postoperative adjuvant chemotherapy. In the patients with Stage IIIB, the efficacy of postoperative adjuvant chemotherapy for recurrence-free survival was not recognized. However, the 5-year recurrencefree survival (66.9\%) in the Stage IIIB patients with postoperative adjuvant chemotherapy in the present study was equivalent to the 5-year disease-free survival (66.4\%) in the Stage III patients with the addition of oxaliplatin in the MOSAIC trial [6]. While it is not feasible to directly compare these outcomes because of the different backgrounds, it has been pointed out that the treatment outcomes of the patients with Stage III colon cancer in Japan were superior to those of the patients with Stage III colon cancer in Europe and America because of the differences of the dissection procedure and the handling of the surgical specimens [18]. However, the outcomes (5-year recurrence-free survival) of the patients with Stage IIIB in the present study were far from satisfactory. Therefore, the addition of oxaliplatin should be considered for patients with Stage IIIB based upon this finding. The 5-year cancer-specific survival rates in Stage IIIB patients were significantly better in those with postoperative adjuvant chemotherapy than in those without. It was concluded that this outcome might be affected by therapy after the recurrence. On the other hand, the outcomes in the Stage IIIC patients both with and without postoperative adjuvant chemotherapy were extremely poor. Therefore, the Stage IIIC patients require the addi- 
tion of oxaliplatin in order to improve their prognosis. In addition, there are few reports about the efficacy of preoperative ("neoadjuvant") chemotherapy for locally advanced operable colon cancer. However, Arredondo et al. [19] reported that preoperative oxaliplatin- and capecitabine-based chemotherapy followed by surgery and chemotherapy for locally advanced colon cancer was safe without apparent increase of early and medium-term complications. A randomised controlled trial (the FOxTROT trial; Fluoropyrimidine Oxaliplatin and Targeted Receptor Pre-Operative Therapy) inspecting the feasibility, safety and efficacy of preoperative chemotherapy for locally advanced operable colon cancer is currently in progress [20]. The FOxTROT trial was designed to assess whether 6 weeks of an effective combination chemotherapy regimen given preoperatively to patients with locally advanced operable colon cancer improves disease-free survival. It appears that this RCT will become one of the indicators of improved long-term oncological outcome of preoperative chemotherapy for locally advanced operable colon cancer.

\section{Conclusion}

However, this was a retrospective study and the indications, regimens and durations of postoperative adjuvant chemotherapy were not fixed throughout. The data were collected and examined at a single institute, and only a small number of patients were enrolled in this study. Based upon the multivariate analysis, the TNM classification, $7^{\text {th }}$ edition, was found to be a significant independent prognostic factor and exhibited an excellent stratification capability. Among the Stage III patients, the prognoses can vary widely between the subgroups (IIIA, IIIB and IIIC). Therefore, a prospective study including the establishment of the optimal regimens in postoperative adjuvant chemotherapy based upon the subgroups of the TNM classification, $7^{\text {th }}$ edition, will be necessary.

\section{Conflict of Interest}

The authors declare that they have no financial or non-financial conflicts of interest related to the subject matter or materials discussed in this article.

\section{References}

[1] Jemal, A., Siegel, R., Ward, E., Hao, Y., Xu, J. and Thun, M.J. (2009) Cancer Statistics, 2009. CA: A Cancer Journal for Clinicians, 59, 225-249. http://dx.doi.org/10.3322/caac.20006

[2] Yoshida, M., Kondo, K. and Tada, T. (2010) The Relation between the Cancer Screening Rate and the Cancer Mortality Rate in Japan. The Journal of Medical Investigation, 57, 251-259. http://dx.doi.org/10.2152/jmi.57.251

[3] Lembersky, B.C., Wieand, H.S., Petrelli, N.J., O’Connell, M.J., Colangelo, L.H., Smith, R.E., Seay, T.E., Giguere, J.K., Marshall, M.E., Jacobs, A.D., Colman, L.K., Soran, A., Yothers, G. and Wolmark, N. (2006) Oral Uracil and Tegafur plus Leucovorin Compared with Intravenous Fluorouracil and Leucovorin in Stage II and III Carcinoma of the Colon: Results from National Surgical Adjuvant Breast and Bowel Project Protocol C-06. Journal of Clinical Oncology, 24, 2059-2064. http://dx.doi.org/10.1200/JCO.2005.04.7498

[4] Twelves, C., Wong, A., Nowacki, M.P., Abt, M., Burris 3rd, H., Carrato, A., Cassidy, J., Cervantes, A., Fagerberg, J., Georgoulias, V., Husseini, F., Jodrell, D., Koralewski, P., Kröning, H., Maroun, J., Marschner, N., McKendrick, J., Pawlicki, M., Rosso, R., Schüller, J., Seitz, J.F., Stabuc, B., Tujakowski, J., Van Hazel, G., Zaluski, J. and Scheithauer, W. (2005) Capecitabine as Adjuvant Treatment for Stage III Colon Cancer. New England Journal of Medicine, 352, 2696-2704. http://dx.doi.org/10.1056/NEJMoa043116

[5] Kuebler, J.P., Wieand, H.S., O’Connell, M.J., Smith, R.E., Colangelo, L.H., Yothers, G., Petrelli, N.J., Findlay, M.P., Seay, T.E., Atkins, J.N., Zapas, J.L., Goodwin, J.W., Fehrenbacher, L., Ramanathan, R.K., Conley, B.A., Flynn, P.J., Soori, G., Colman, L.K., Levine, E.A., Lanier, K.S. and Wolmark, N. (2007) Oxaliplatin Combined with Weekly Bolus Fluorouracil and Leucovorin as Surgical Adjuvant Chemotherapy for Stage II and III Colon Cancer: Results from NSABP C-07. Journal of Clinical Oncology, 25, 2198-2204. http://dx.doi.org/10.1200/JCO.2006.08.2974

[6] André, T., Boni, C., Navarro, M., Tabernero, J., Hickish, T., Topham, C., Bonetti, A., Clingan, P., Bridgewater, J., Rivera, F. and de Gramont, A. (2009) Improved Overall Survival with Oxaliplatin, Fluorouracil, and Leucovorin as Adjuvant Treatment in Stage II or III Colon Cancer in the MOSAIC Trial. Journal of Clinical Oncology, 27, 3109-3116. http://dx.doi.org/10.1200/JCO.2008.20.6771

[7] NCCN (2013) http://www.nccn.org/

[8] ESMO (2013) http://www.esmo.org/

[9] NICE (2013) http://www.nice.org.uk/

[10] André, T., Boni, C., Mounedji-Boudiaf, L., Navarro, M., Tabernero, J., Hickish, T., Topham, C., Zaninelli, M., Clingan, 
P., Bridgewater, J., Tabah-Fisch, I. and de Gramont, A., Multicenter International Study of Oxaliplatin/5-Fluorouracil/ Leucovorin in the Adjuvant Treatment of Colon Cancer (MOSAIC) Investigators (2004) Oxaliplatin, Fluorouracil, and Leucovorin as Adjuvant Treatment for Colon Cancer. New England Journal of Medicine, 350, 2343-2351. http://dx.doi.org/10.1056/NEJMoa032709

[11] Aballéa, S., Chancellor, J.V., Raikou, M., Drummond, M.F., Weinstein, M.C., Jourdan, S. and Bridgewater, J. (2007) Cost-Effectiveness Analysis of Oxaliplatin Compared with 5-Fluorouracil/Leucovorin in Adjuvant Treatment of Stage III Colon Cancer in the US. Cancer, 109, 1082-1089. http://dx.doi.org/10.1002/cncr.22512

[12] Japanese Society for Cancer of the Colon and Rectum (2009) Japanese Classification of Colorectal Carcinoma. 2nd Edition, Kanehara \& Co., Ltd., Tokyo.

[13] Sobin, L.H., Gaspodarowicz, M. and Wittekind, C. (2009) TNM Classification of Malignant Tumors. 7th Edition, Wiley-Blackwell, New York.

[14] Gunderson, L.L., Jessup, J.M., Sargent, D.J., Greene, F.L. and Stewart, A.K. (2010) Revised TN Categorization for Colon Cancer Based on National Survival Outcomes Data. Journal of Clinical Oncology, 28, 264-271. http://dx.doi.org/10.1200/JCO.2009.24.0952

[15] Gunderson, L.L., Jessup, J.M., Sargent, D.J., Greene, F.L. and Stewart, A.K. (2010) Revised Tumor and Node Categorization for Rectal Cancer Based on Surveillance, Epidemiology, and End Results and Rectal Pooled Analysis Outcomes. Journal of Clinical Oncology, 28, 256-263. http://dx.doi.org/10.1200/JCO.2009.23.9194

[16] Gao, P., Song, Y.X., Wang, Z.N., Xu, Y.Y., Tong, L.L., Sun, J.X., Yu, M. and Xu, H.M. (2013) Is the Prediction of Prognosis Not Improved by the Seventh Edition of the TNM Classification for Colorectal Cancer? Analysis of the Surveillance, Epidemiology, and Results (SEER) Database. BMC Cancer, 13, 123. http://dx.doi.org/10.1186/1471-2407-13-123

[17] Sakamoto, J., Ohashi, Y., Hamada, C., Buyse, M., Burzykowski, T. and Piedbois, P., Meta-Analysis Group of the Japanese Society for Cancer of the Colon and Rectum, Meta-Analysis Group in Cancer (2004) Efficacy of Oral Adjuvant Therapy after Resection of Colorectal Cancer: 5-Year Results from Three Randomized Trials. Journal of Clinical Oncology, 22, 484-492.

[18] Hamaguchi, T., Shirao, K., Moriya, Y., Yoshida, S., Kodaira, S. and Ohashi, Y., NSAS-CC Group (2011) Final Results of Randomized Trials by the National Surgical Adjuvant Study of Colorectal Cancer (NSAS-CC). Cancer Chemotherapy and Pharmacology, 67, 587-596. http://dx.doi.org/10.1007/s00280-010-1358-1

[19] Arredondo, J., Pastor, C., Baixauli, J., Rodríguez, J., González, I., Vigil, C., Chopitea, A. and Hernández-Lizoáin, J.L. (2013) Preliminary Outcome of a Treatment Strategy Based on Perioperative Chemotherapy and Surgery in Patients with Locally Advanced Colon Cancer. Colorectal Disease, 15, 552-557. http://dx.doi.org/10.1111/codi.12119

[20] FOxTROT Collaborative Group (2012) Feasibility of Perioperative Chemotherapy for Locally Advanced, Operable Colon Cancer: The Pilot Phase of a Randomised Controlled Trial. The Lancet Oncology, 13, 1152-1160. http://dx.doi.org/10.1016/S1470-2045(12)70348-0 
Scientific Research Publishing (SCIRP) is one of the largest Open Access journal publishers. It is currently publishing more than 200 open access, online, peer-reviewed journals covering a wide range of academic disciplines. SCIRP serves the worldwide academic communities and contributes to the progress and application of science with its publication.

Other selected journals from SCIRP are listed as below. Submit your manuscript to us via either submit@scirp.org or Online Submission Portal.
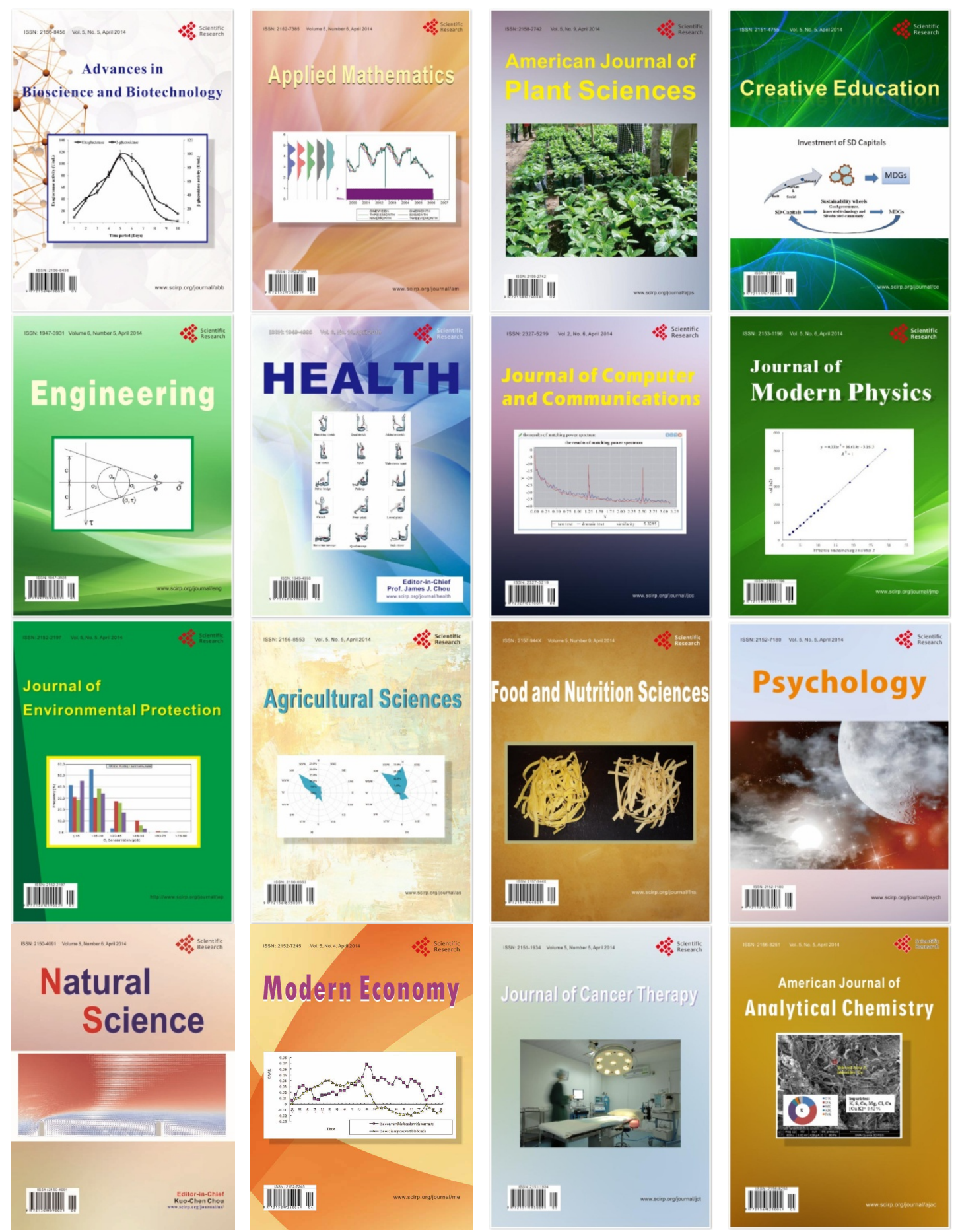